\title{
Structural and Charge Density Properties of Manganese Sulfide
}

\author{
S.Saravanakumar, S. Sasikumar, D. Sivaganesh, R. Rajajeyaganthan
}

\begin{abstract}
Single phased Manganese Sulfide was analyzed by powder X-ray diffraction (PXRD) data sets with cubic structure. The simulated XRD data sets were used to analyze the structure of manganese sulfide. The powder profile refinements were done by Rietveld profile refinement technique. The refinement results were subjected to analyze the charge density analysis using structure factors. The chemical bonding nature between Mn and $S$ were analyzed by charge density distribution studies through maximum entropy method. From MEM analsysis, it found that the bonding between Mn and $S$ atoms is ionic in nature.
\end{abstract}

Keywords : Rietveld refinement, bonding nature, crystal structure, maximum entropy method.

\section{INTRODUCTION}

R ecently, dilute magnetic semiconductors (DMS) have focused more attention, due to combined semiconducting and magnetic properties [1]. Manganese Sulfide $(\mathrm{MnS})$ is a semiconducting material with a wide band gap of $\sim 3.1 \mathrm{eV}$. The MnS materials are used in important optoelectronic devices such as solar cells, solar coatings applications, sensors, memories and photoconductors [2-5].

The present report details are the structural properties of MnS. The structural property has been experimentally analyzed via powder X-ray diffraction (PXRD) and Rietveld profile refinements [6]. The primary aim of this present work is to study the distribution of charges inside the unit cell of the $\mathrm{MnS}$ samples. The electron plays an important role in the fundamental properties of semiconducting materials. In this aspect, an electron density distribution study is getting great importance.

The electron density distribution study is used to analyze the bonding features of the materials. Maximum entropy method is an important tool for analyzing the electron density distributions and is used for getting the detailed information about the electronic properties and nature of the bonding. In general, the electronic property of the materials plays a vital role in electrical properties, which helps to know about the

Revised Manuscript Received on December 09, 2019.

* Correspondence Author

S. Saravanakumar*, Department of Physics, International Research Centre,Kalasalingam Academy of Research and Education, Krishnankoil 626126.Tamil Nadu, India. Email: saravanaphysics@ gmail.com

D. Sivaganesh, Department of Physics, International Research Centre,Kalasalingam Academy of Research and Education, Krishnankoil 626126.Tamil Nadu, India. Email: ganesh.siva650@ gmail.com

S. Sasikumar, Department of Physics, International Research Centre,Kalasalingam Academy of Research and Education, Krishnankoil 626126.Tamil Nadu, India. Email: sasikuhan@ gmail.com

R. Rajajeyagandhan, Department of Chemistry, International Research Centre,Kalasalingam Academy of Research and Education, Krishnankoil 626126.Tamil Nadu, India. Email: rajajeyaganthan.r@klu.ac.in bonding nature between constituent atoms. The charge density maps and chemical bonding features inside the unit cell of $\mathrm{MnS}$ are reconstructed by maximum entropy Method (MEM) from the structure factors evolved by Rietveld profile refinement [6].

\section{RESULTS AND DISCUSSION}

\section{A. PXRD studies and Rietveld refinement analysis}

Single phased X-ray powder diffraction data sets of $\mathrm{MnS}$ materials were successfully simulated by using the software "Findit" [7]. The Cubic structure can be considered with a space group of Fm-3m and the cell constants $a=b=c=5.224 \AA$. The atomic position coordinates for $\mathrm{Mn}$ and $\mathrm{S}$ atoms were assigned as given in table 1 .

In order to find more information about crystal structure, the crystal refinement was done by Rietveld refinement performed using JANA2006 [8] software by the PXRD data. The fitted XRD profiles for MnS material is shown in fig. 1 . Fig. 1 shows a good agreement between the observed X-ray profiles and calculated X-ray profiles of $\mathrm{MnS}$. In the overall refinement, the difference between observed and calculated profiles showed that there is a perfect matching with experimental data. The results of Rietveld profile refinement with acceptable R-factors such as Rp, Robs and GOF extracted from profile refinement results and the values are presented in table 1.

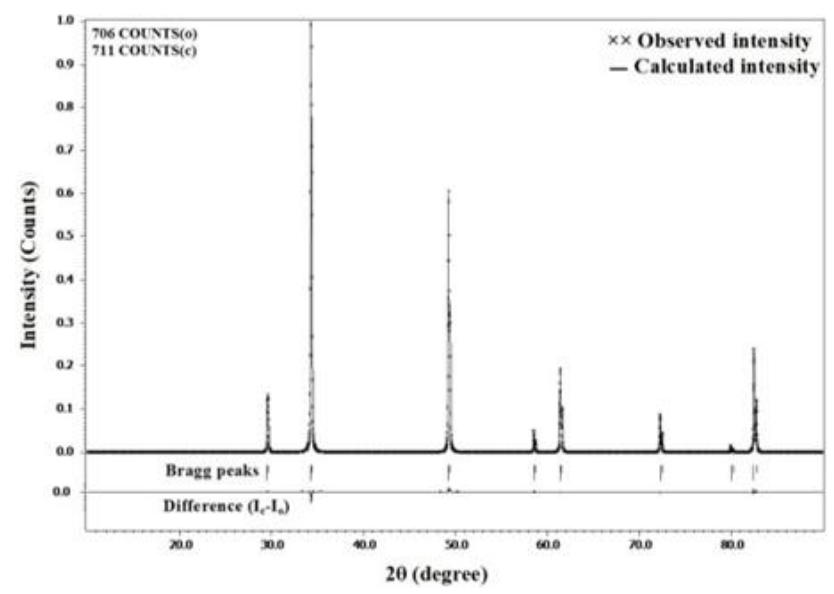

Fig. 1.Fitted X-ray profiles for MnS. 
Table I - REFINED STRUCTURAL PARAMETERS OF MAGNESIUM SULFIDE

\begin{tabular}{|c|c|}
\hline Parameters & MnS \\
\hline $\mathrm{a}=\mathrm{b}=\mathrm{c}(\AA)$ & 5.224 \\
\hline$\alpha=\beta=\gamma\left({ }^{\circ}\right)$ & 90 \\
\hline Space group & Fm-3m \\
\hline Volume $(\AA 3)$ & 142.52 \\
\hline Density $(\mathrm{gm} / \mathrm{cc})$ & 4.05 \\
\hline $\mathrm{Rp}(\%)$ & 2.81 \\
\hline Rwp $(\%)$ & 7.90 \\
\hline Robs $(\%)$ & 0.77 \\
\hline GOF & 0.21 \\
\hline $\mathrm{F}(000)$ & 164 \\
\hline \multicolumn{2}{|c|}{ Thermal parameters } \\
\hline Mn & 0.884 \\
\hline $\mathrm{S}$ & 1.745 \\
\hline Atomic positions (x y z) \\
\hline Mn & 000 \\
$\mathrm{~S}$ & $1 / 21 / 21 / 2$ \\
\hline
\end{tabular}

Table II - THE OBSERVED AND CALCULATED STRUCTURE FACTOR VALUES FROM MEM ANALYSIS

\begin{tabular}{|c|c|c|c|c|c|}
\hline $\mathbf{h}$ & $\mathbf{k}$ & $\mathbf{l}$ & $\mathbf{F}_{\mathbf{o}}$ & $\mathbf{F}_{\mathbf{c}}$ & $\boldsymbol{\sigma}\left(\mathbf{F}_{\mathbf{o}}\right)$ \\
\hline 1 & 1 & 1 & 30.092 & 29.959 & 0.329 \\
0 & 0 & 2 & 117.299 & 118.161 & 1.299 \\
2 & 0 & 2 & 98.340 & 97.666 & 1.030 \\
1 & 1 & 3 & 23.450 & 23.118 & 0.246 \\
2 & 2 & 2 & 84.083 & 84.324 & 0.894 \\
0 & 0 & 4 & 73.944 & 74.511 & 0.897 \\
3 & 1 & 3 & 16.666 & 17.115 & 0.246 \\
2 & 0 & 4 & 67.482 & 66.799 & 1.068 \\
\hline
\end{tabular}

\section{B. Charge density analysis}

Charge density distribution studies are very useful to understand the physical properties of the materials, like optical and electrical properties. In this work, the charge densities were calculated inside the unit cell using maximum entropy method [9]. Each unit cell of the sample was divided into $64 \times 64 \times 64$ pixels along the three crystallographic direction and each pixel fixed as $\mathrm{F}_{000} / \mathrm{a}_{0}{ }^{3}$ using PRIMA [10] and VESTA [11] software. Fig. 2 shows the charge density distributions in 3D with iso-surfaces. Fig. 3 shows the 2D maps on (100) plane and the contour interval between the ions is $0-1 \mathrm{e} / \AA^{3}$. The counter step interval is $0.04 \mathrm{e} / \AA^{3}$. From the 2D planes, the contour lines show the accumulation of charges between the $\mathrm{Mn}-\mathrm{S}$ bonds. This authenticates the $\mathrm{Mn}$ $\mathrm{S}$ bond is ionic in nature. These results are consistent with PXRD data. Fig. 4 shows that the 1D charge density profile along $\mathrm{Mn}-\mathrm{S}$ bonding direction, which also elucidate the length of the bond and mid bond charge density and their values are presented in table 3 . The mid bond electron densities revealed that the $\mathrm{Mn}-\mathrm{S}$ bond is ionic in nature. The iso-surface level is $0-1 \mathrm{e} / \AA^{3}$. The parameters from MEM analysis are presented in table 4.

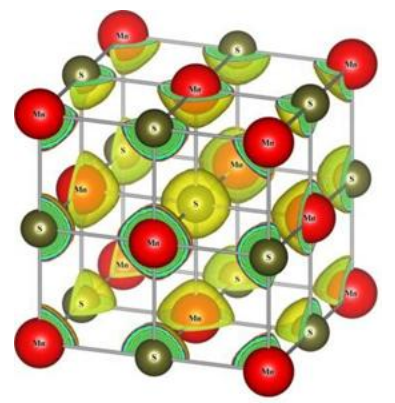

Fig. 2.3D electron density of $\mathrm{Mn}$

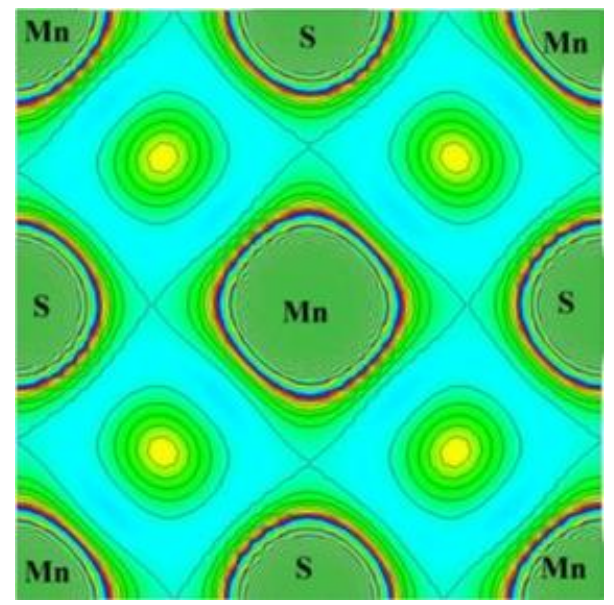

Fig. 3.2D electron density distribution on (100) plane for MnS.

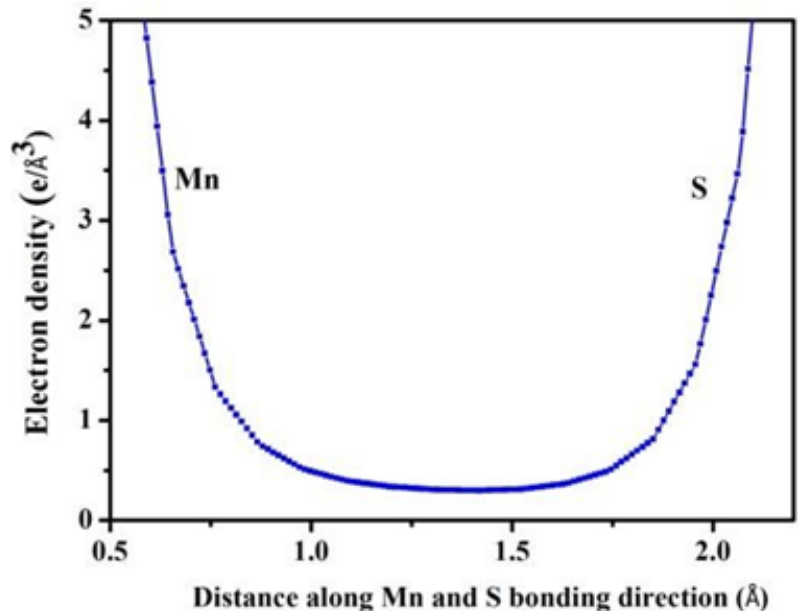

Fig. 4.1D charge density variation profiles for $\mathrm{Mn}-\mathrm{S}$ bond.

Table III - CHARGE DENISY PAPRAMETER OF MN-S BOND

\begin{tabular}{|c|c|c|}
\hline Bond length $(\mathbf{\AA})$ & $\begin{array}{c}\text { Distance from Mn } \\
\text { ion }(\stackrel{\AA}{\mathbf{A}})\end{array}$ & $\begin{array}{c}\text { Mid bond electron } \\
\text { density }\left(\mathbf{e} / \AA^{\mathbf{3}}\right)\end{array}$ \\
\hline 2.612 & 1.417 & 0.2989 \\
\hline
\end{tabular}

TABLE IV.PARAMETERS OBTAINED FROM MEM ANALAYSIS

\begin{tabular}{|c|c|}
\hline Parameters & MnS \\
\hline Number of cycles & 155 \\
\hline $\mathrm{R}_{\mathrm{MEM}}(\%)$ & 0.37 \\
\hline $\mathrm{wR}_{\mathrm{MEM}}(\%)$ & 0.35 \\
\hline
\end{tabular}

\section{CONCLUSION}

In the present work, Manganese Sulfide was successfully investigated by powder X-ray diffraction (PXRD) data sets using simulated XRD data sets by using Findit software. Rietveld profile refinement technique revealed the cubic structure of $\mathrm{MnS}$ material. The bonding nature between the ions were investigated through MEM analysis. The bonding characteristics revealed that the ionic behaviour is exist between the $\mathrm{Mn}$ and $\mathrm{S}$ atoms. 


\section{ACKNOWLEDGEMENTS}

Authors would like to gratefully acknowledge Kalasalingam Academy of Research and Education for constant supporting to this research work.

\section{REFERENCES}

1. D. Fan, H. Wang, Y. Zhang, J. Cheng, B. Wang, H. Yan, "Preparation of crystalline MnS thin films by chemical bath deposition", Mater. Chem. Phys. vol. 80, pp. 44-47, 2003.

2. C. Gümüs, C. Ulutas, R. Esen, O.M. Ozkendir, Y. Ufuktepe, "Preparation and characterisation of crystalline $\mathrm{MnS}$ thin films by chemical bath deposition", Thin Solid Films vol. 492, pp. 1-5, 2005.

3. D. Fan, X. Yang, H. Wang, Y. Zhang, H. Yan, "Photoluminescence of MnS thin film prepared by chemical bath deposition", Physica B vol. 337, pp. 165-169, 2003.

4. C.D. Lokhande, A. Ennaoui, P.S. Patil, M. Giersig, M. Muller, K. Diesner, H. Tributsch, "Process and characterization of chemical bath deposition manganese sulphide (MnS) thin film", Thin Solid Films vol. 330, pp. 70-75, 1998.

5. R. Tappero, P. D'Arco, A. Lichanot, "Electronic structure of $\alpha-\mathrm{MnS}$ (alabandite): an ab initio study Chem". Phys. Lett. Vol. 273, pp. 83-90, 1997.

6. H.M. Rietveld, J. Appl. Crystallogr., vol. 2, pp. 65, 1969.

7. http://www.se.iucr.org/iucr-top/index.html

8. V. Petricek, M. Dusek, L. Palatinus Jana, The crystallographic computing system (Institute of Physics, Praha, Czech Republic), p. 2006.

9. D.M. Collins, Electron density images from imperfect data by iterative entropy maximization, Nature, vol. 298, pp. 49-51, 1982.

10. K. Momma, F. Izumi, VESTA 3 for three-dimensional visualization of crystal, volumetric and morphology data, J. Appl. Crystallogr. vol. 44, pp.1272-1276, 2011.

11. K. Momma, F. Izumi, Comm. Crystallogr. Comput. IUCr Newslett., vol. 7, pp. 106, 2006.

\section{AUTHORS PROFILE}

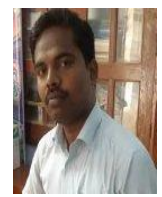

S. Saravanakumar is working as an assistant professor at Kalasalingam University and he received his Ph.D. degree in 2015 at Madurai Kamaraj University, India. His main research interest is materials science. He has published 26 articles in journals with over 107 citations.

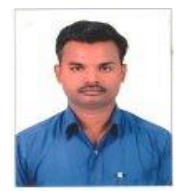

S. Sasikumar received his Ph.D degree in 2018 at Madurai Kamaraj University, India. His research interest is the applications of piezo - electric materials. He has published 19 research articles in reputed journal with 56 citations.

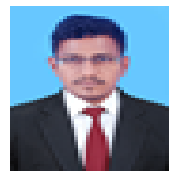

D. Sivaganesh is a $\mathrm{Ph} . \mathrm{D}$ student at Kalasalingam University, India. His research interest is structural and photoluminescence properties of phosphor materials.

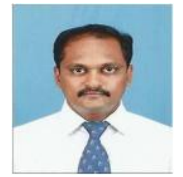

Dr. Rajajeyagantha Ramanathan completed his B.Sc., Applied Sciences from Coimbatore Institute of Technology, Coimbatore and M.Sc., Applied Chemsitry from National Institute of Technology, Tiruchirappalli. He was awarded "Best Outgoing Student" with a gold medal in M.Sc. He completed his Ph.D (Surface Science) under TWAS-CNPq fellowhip from Federal University of Rio Grande do Sul, RS, Brazil. 